\title{
THE LEVEL OF DECENTRALIZATION IMPACT ON THE BULGARIAN SOCIAL HEALTH CARE COMPETITIVENESS
}

\author{
Venelin Terziev ${ }^{1}$ and Stoyanka Petkova - Georgieva ${ }^{2}$ \\ ${ }^{1}$ Full Member of the Russian Academy of Natural History, Professor, Eng., D.Sc. (National \\ Security), D.Sc. (Economics), D.Sc. (Social Activities), Ph.D., Russian Academy of Natural History, \\ Moscow, Russia, Vasil Levski National Military University, Veliko Tarnovo, Bulgaria University of \\ Rousse, Rousse, Bulgaria, terziev@skmat.com \\ ${ }^{2}$ Associate Professor, Ph.D., University „Prof. d-r Assen Zlatarov” - Bourgas, Bulgaria, \\ s.p.petkova@gmail.com
}

\begin{abstract}
One of the most significant characteristics on which the Bulgarian social health care system competitiveness depends is the level of decentralization. In this study the authors explain a methodology for estimating the level of decentralization by using the knowledge of the so-called performance measurement system (PMS). The established theoretical model is tested among health care managers in 78 sub-divisional units randomly chosen among the Bulgarian health care system - facilities and hospitals. There have been made several conclusions that could be a base for future research and discussion.
\end{abstract}

Keywords: competitiveness, impact, level of decentralization, Bulgarian health care system.

\section{INTRODUCTION}

One of the most significant and traditional instruments for management competitiveness increasing is the socalled "performance measurement system" (PMS). The present research is provided among facilities and hospitals randomly chosen from the Bulgarian health care system. The specific feature that was necessary to be available was the management and organization structure of the examined hospital or facility to be like a business organization with a lot of sub-divisional structures on many levels of decentralization. Their use can essentially be traced back to two problem areas. Using the existing data without focusing on management bottlenecks demands a manipulation of large amount of numbers with little useful information, thence with restricted practical use. Another disadvantage is that they usually operate with valuable and based on past experience quantities.

Because of the restrictions of the paper amount we will only present several steps of the conducted research. The aim of the paper is to summarize theoretical interdependencies among the determinants that influence the level of the decentralization and the structure of PMS and also to present attained results of the carried-out investigation. The accent of the research is to give some important methodology's steps of how the PMS can be useful for competitiveness increasing.

\section{THEORETICAL STUDY}

Theory and earlier evidence suggest that decisions relating to decentralization and PMS choices are made simultaneously and that these choices are influenced by a number of exogenous factors. The impact of 
interdependencies among subunits and cost of transferring knowledge on these choices is discussed in turn.

In the contemporary literature a lot of "new" versions of systems of performance measures have been suggested which addressed these deficiencies. Depending on what conception the PMS is based, they can be classified to balanced and focused. The balanced scorecard is the usual representative in the first group and the system of selective performance measures is the representative of the second (Bouwens, Abernethy, 2000).

The design of PMS for the strategic control systems should be based on the return of management (ROM) as a maximization criterion and manager's time and attention is a scarce resource, which has to be optimized (Terziev, Petkova - Georgieva, 2019). This measure shows the return of investments in scarce resources (e.g. manager's time and attention). ROM is not a quantitative amount, so the manager as an intuitive estimate can only determine it. As a control quantity it can indicate directions, but not definite targets.

If we apply the ideas behind ROM to performance measure systems, it would be advisable to differentiate between diagnostic and interactive PMS (Terziev, Petkova - Georgieva, 2019a). Both types of performance measure systems described are needed for successfully controlling of the business. For this reason, it is necessary to develop an improved active PMS which passes at two basic stages. Firstly, filtration and selection only of these measures, that describe the value creation chain of an organization - the design of PMS. The second stage is focused on the leading narrow events and factors (Christie, Joye, Watts, 1993).

Our study is based on the analytical frameworks developed by Jensen and Meckling (Keating, 1997) and Milgrom and Roberts (Simons, 2017). The model assesses choices relating to level of decentralization and two forms of subunit performance metrics, namely, aggregated performance measures (eg. profit or ROI) and disaggregated performance measures or what we refer to as specific performance measures (e.g. production expenditure, R\&D, sales revenues). The simultaneous equation model can be summarized as follows:

- DECEN = function (AGG, SPEC, SI, KTC).

- $A G G=$ function (DECEN, SPEC, SI, KTC).

- $\mathrm{SPEC}=$ function (DECEN, AGG, SI, KTC).

DECEN - Decentralization; AGG - Aggregated PMs; SPEC - Specific PMs; SI - Subunit Interdependencies

KTC - Knowledge Transfer Cost.

We conducted our research in Bulgarian health care facilities and hospitals (the real names of the health care organizations are confident). The necessary data for the test of the model was obtained from a survey of 78 managers from 18 divisions of the Bulgarian facilities and hospitals. We find that decentralization is positively and significantly related to knowledge transfer costs and negatively related to levels of subunit interdependencies. The use of aggregated PMs is significantly related to subunit interdependencies. However, the significance and direction of the relation depends on the nature of the interdependencies. When the actions of divisional managers influence the performance of other divisions the relationship is negative but not significant. However, we found that the use of aggregated PMs increases when the divisional manager's own performance is influenced by actions of other divisional managers. Only knowledge transfer costs and the level of decentralization influenced the use of specific PMs. Statistical information about the number of the Bulgarian hospitals for long-term treatment is given on Table 1.

Table 1. The number of beds in the Bulgarian health care facilities and hospitals in 2018.

\begin{tabular}{|l|l|l|}
\hline TYPES OF HEALTH ESTABLISHMENTS & NUMBER & BEDS \\
\hline Health establishments for hospital care - total $^{*}$ & 321 & 49589 \\
\hline Multi-profile hospitals & 112 & 25353 \\
\hline Multi - profile hospitals for acute treatment & 110 & 25238 \\
\hline Specialized hospitals & 65 & 7121 \\
\hline Specialized hospitals for active treatment & 33 & 3100 \\
\hline
\end{tabular}


IJASOS- International E-Journal of Advances in Social Sciences, Vol. V, Issue 15, December 2019

\begin{tabular}{|c|c|c|}
\hline Specialized hospitals for long-term treatment and rehabilitation & 10 & 930 \\
\hline Specialized hospitals for rehabilitation & 21 & 2951 \\
\hline Psychiatric hospitals & 12 & 2225 \\
\hline Private establishment for hospital care & 111 & 11195 \\
\hline Health facilities for outpatient care & 2029 & 1163 \\
\hline Medical centers & 702 & 825 \\
\hline Dental centers & 50 & 13 \\
\hline Medical-dental centers & 50 & 53 \\
\hline Diagnostic and consulting centers & 112 & 272 \\
\hline Medical-diagnostic and medical - laboratory centers & 1115 & - \\
\hline Outpatient individual practices for primary medical care & 3396 & - \\
\hline Outpatient individual practices for primary dental care & 5062 & - \\
\hline Outpatient group practices for primary medical care & 214 & - \\
\hline Outpatient group practices for primary dental care & 372 & - \\
\hline Outpatient individual practices for specialized medical care & 2949 & - \\
\hline Outpatient individual practices for specialized dental care & 85 & - \\
\hline Outpatient group practices for specialized medical care & 139 & - \\
\hline Outpatient group practices for specialized dental care & 1 & - \\
\hline \multicolumn{3}{|l|}{ Other health care and health establishments } \\
\hline Complex oncological centers & 7 & 1145 \\
\hline Dermato - venereological centers & 5 & 50 \\
\hline Mental health centers & 12 & - \\
\hline Centers for urgent medical aid & 27 & - \\
\hline Centers for transfusional haematology & 4 & - \\
\hline Homes for medico-social care for children & 17 & 1114 \\
\hline Hospices & 45 & 1079 \\
\hline National centers without beds & 5 & - \\
\hline Regional health inspectorates & 28 & - \\
\hline
\end{tabular}

Sources: Bulgarian National Centre of Public Health and Analysis (BNCPHA) 
${ }^{*}$ Note: A number of specialized hospitals are included in the total without featuring in the categories, listed in Table 1.

\section{- Interdependencies}

Based on prior literature, we would thus expect that subunit performance measures would become less important as interdependencies increase. This is expected to be the case with both types of subunit measures - aggregated profit measures as well as specific measures relating to production efficiency, R\&D costs and quality. Specific measures are also influenced by actions taken in interdependent subunits and thus will be less informative about the actions of individual subunit managers. In sum, we expect a negative relation between subunit interdependencies and both components of the subunit PMS.

The operating externalities created by such dependencies directly influence top health care management's decision to delegate decision rights. The existence of operating externalities implies that there are benefits to be gained by coordinating the activities of the subunits. When local health care managers are delegated decision rights, they will optimize their own subunit's profit rather than consider the impact of their decisions on other units. Hence, ceteris paribus, the cost associated with decentralization will increase as operating dependencies increase. Top management will attempt to minimize the opportunity for suboptimal decision making by centralizing decision making. In other words, centralization will be the least cost option when interdependencies are high. Interdependencies will also significantly influence the design and use of PMSs. Interdependencies among organizational subunits vary along a continuum. At one end of the continuum subunits operate autonomously where the only form of interdependence is with corporate services, to the other end where subunits have reciprocal interdependencies. This is where subunits are required to trade their intermediate products with each other. In other words, the demand functions of the subunits firm may be dependent or they may have joint supply and cost functions.

However, the impact of interdependencies on the use of PMSs is not due to the effect of operating externalities, as such. Rather, it is the influence that interdependencies have on the behavior of subunit managers when performance is measured based on metrics that are influenced by actions of other subunits (Jensen, Meckling, 1992). They argued that firm level profit would be superior to the subunit profit measure due to the "noise" created by the activities performed in other subunits. Not only does the subunit profit measure become less informative in assessing managerial performance, superiors will also use firm profit to encourage subunit managers to co-operate. In contrast, when interdependencies are low, subunit profit will become increasingly important.

\section{- Knowledge Transfer Costs}

There is some ambiguity in literature how to define knowledge transfer costs. The variable appears to have two dimensions: one capturing specific knowledge (i.e. knowledge impacted at the subunit level) and second capturing environmental factors (i.e. competition, strategy, size, growth). While it is possible that the two dimensions are correlated, our model is developed to enable a more careful exposition of the relation among these two dimensions and organization design choices.

\section{- Specific Knowledge}

The Specific knowledge is information that is impacted at the subunit level. It occurs due to the costs of transferring information to higher levels in the hierarchy. Subordinate health care managers obtain specific knowledge relating to markets, technology, suppliers and other factors relating to their external environment. The level of specific knowledge increases as the complexity associated with these factors increases. As complexity increases it becomes more costly to transfer the information required for decision making upwards in the organization. These costs relate not only to the systems required to transmit the information effectively but also the costs of sub-optimal decision making when the cognitive limitations of top management preclude the efficient processing of information. Thus, as the level of specific knowledge increases it comes less costly to decentralize than to invest in processes and systems to increase the information processing capabilities of a centralized management structure.

The delegation of decision rights that follows from the presence of specific knowledge will prompt supervisors to rely on aggregate performance measures to encourage subunit managers to optimally use the specific knowledge. This would imply an increase of aggregate measure use. It is also argued that aggregate measures are often too late (i.e. insensitive to decisions) and/or too crude (not accurate) to assess the effect of managerial decisions (Khandwalla, 2010; Nagar, 2014). This implies that the use of aggregate measure will decrease when specific knowledge increases. It is, therefore, expected that specific knowledge has a negative effect on the use of aggregate performance measures.

We do, however, expect a positive and significant relation between SK and the use of specific performance 
measures. In the presence of SK specific measures can be informative about pivotal activities within the subunit. Compared with aggregated measures, specific measures are designed to provide incremental information on the subordinate's performance with respect to the pivotal activities. To the subordinate including specific measures decreases the risk that his contribution is insufficiently captured by the performance measurement system. After controlling for decentralization, we, therefore, expect the relation between specific knowledge and specific measures to be positive.

\section{- Environmental Conditions}

Based on prior research (Kaplan, Atkinson, 1998) we incorporate three variables to capture the knowledge transfer costs associated with environmental factors: growth opportunities, competition and size. We expect environment factors to have differential effects on design choices.

\section{$\checkmark$ Impact on Decentralization}

The ability of top management to effectively "micro-manage" at the subunit level becomes increasingly difficult in firms pursuing a growth strategy. The delegation of decision rights enables subunit health care managers to scan the environment for new opportunities and threats and respond accordingly. Similar arguments apply for firms pursuing strategies that involve high levels of competition. To be successful in a highly competitive environment requires a decision-making structure that is flexible, dynamic and adaptable (Milgrom, Roberts, 2015). This requires a decentralized structure where subunit managers have the authority to respond quickly to changes in competitive conditions. Size is also an important determinant of decentralization. The sheer volume of information required to manage large organizations makes it impossible or prohibitively costly for decision making to be centralized. In sum, ceteris paribus, decentralization will be the least cost solution in firms that are large, pursuing a high growth strategy and facing intense competition. We, therefore, expect a positive relation between decentralization and growth, size and competition (Todorov, 2018a; Todorov, 2015a)

\section{$\checkmark$ Impact on Choice of Performance Metric}

There is no reason to expect a separate effect of growth or size on choice of performance metric other than through the creation of specific knowledge. The choice of performance metrics will be due to the development of specialized knowledge and top management's attempt to minimize opportunistic behavior, rather than any direct effect of growth or size on PMS design. On the other hand, prior literature suggests that competition may in fact directly influence the relative importance placed on performance measures by top management (Milgrom, Roberts, 2015). There is no theoretical reason for expecting that the choice of performance measure (aggregated or specific) will differ dependent on level of competition.

\section{- Hypotheses}

Table 2 and the following hypotheses summarize the above discussion:

$\mathrm{H} 1$ : The level of decentralization decreases as the subunit operating interdependencies increase and increases as the level of subunit specific knowledge, subunit growth opportunities, size and competition increase;

$\mathrm{H} 2$ : The use of aggregated subunit performance measures decreases when subunit interdependencies increase and increases when competition intensifies;

H3: The use of specific subunit performance measures decreases as subunit interdependencies increase and increases as subunit specific knowledge increases and competition intensifies.

Table 2. Main effects investigated in this research.

\begin{tabular}{|l|l|l|l|}
\hline $\begin{array}{l}\text { Factor affecting } \\
\text { organizational design }\end{array}$ & $\begin{array}{l}\text { 2. Decentraliz } \\
\text { ation level } \\
\text { (DECEN) }\end{array}$ & $\begin{array}{l}\text { Own-level performance } \\
\text { measure } \\
\text { (AGG) }\end{array}$ & $\begin{array}{l}\text { Specific performance } \\
\text { measure } \\
\text { (SPEC) }\end{array}$ \\
\hline 3. Knowledge Transfer Costs & & & + \\
\hline *Specific Knowledge (SK) & + & - & \\
\hline *Environmental Conditions & & & \\
\hline
\end{tabular}


IJASOS- International E-Journal of Advances in Social Sciences, Vol. V, Issue 15, December 2019

\begin{tabular}{|l|l|l|l|}
\hline -Growth & + & & \\
\hline -Size & + & & \\
\hline -Competition & + & + & + \\
\hline 4. Subunit interdependencies & - & - & - \\
\hline
\end{tabular}

\section{INVESTIGATION RESULTS}

Our sample included divisions that were defined as subunits that report directly to the Chief Executive Officer (CEO) or Chief Operating Officer (COO) of the business organization from The Bulgarian health care system. The used survey instruments are checklists. Summary statistics for each variable are presented in Table 3.

Table 3. Results from the research study.

\begin{tabular}{|c|c|c|c|c|c|}
\hline Variable & Mean & $\begin{array}{l}\text { Standard } \\
\text { Deviation }\end{array}$ & $\begin{array}{l}\text { Media } \\
\mathrm{n}\end{array}$ & Minimum & Maximum \\
\hline 5. DECEN & 5.22 & 1.05 & 5.4 & 2.4 & 7 \\
\hline AGG & 57.28 & 24.63 & 50 & 0 & 100 \\
\hline SPEC & 30.27 & 21.04 & 30 & 0 & 80 \\
\hline SK & 32.82 & 5.83 & 33.5 & 19 & 42 \\
\hline SUPPLY & 32.88 & 39.15 & 15 & 0 & 150 \\
\hline IMPACT1 & 4.29 & 1.87 & 4 & 1 & 7 \\
\hline IMPACT2 & 4.15 & 1.85 & 4 & 1 & 7 \\
\hline GROWTH & 11.12 & 1.59 & 11 & 8 & 14 \\
\hline SIZE & 5.01 & 2.26 & 5 & 1 & 8 \\
\hline RSIZE & 27.26 & 20.18 & 20 & 1 & 80 \\
\hline CPERF & 9.65 & 2.14 & 10 & 5 & 14 \\
\hline PPERF & 8.94 & 2.69 & 9 & 2 & 14 \\
\hline INT_AGG & 57.78 & 25.20 & 52.5 & 0 & 100 \\
\hline INT_SPEC & 25.09 & 21.48 & 20 & 0 & 100 \\
\hline COMP & 20.28 & 4.10 & 21 & 4 & 28 \\
\hline
\end{tabular}

DECEN - summary statistics for decentralization; AGG - use of own-level aggregated performance measures; SPEC - use of specific measures; SK - specific knowledge; SUPPLY - operating interdependencies; GROWTH - growth opportunities; SIZE - size of the unit; PPERF - past performance; IMPACT1- impact of unit on performance of other units in firm; IMPACT2 - impact of other units in firm on performance of own unit; RSIZE - relative size of unit in firm; COMP - degree of competition; INT_AGG intensity of own-level aggregated measures; INT_SPEC - intensity of specific measures; CPERF experience and current performance;

The next table captures the use of the decentralization as a part of the all checklists (Table 4): 
CHECKLIST for estimating of variable "decentralization"

\section{Decentralization (DECEN)}

In this section we would like you to compare your influence with the influence of your superior on the following decisions:

- Strategic decisions (e.g., development of new products; enter and develop new markets; your unit's strategy);

- Investment decisions (e.g., acquiring new assets and financing investment projects; information systems);

- Marketing decisions (e.g., campaigns; pricing decisions);

- Decisions regarding internal processes (setting production/sales priorities; inputs used and/or processes employed to fill orders; contracting input suppliers);

- Human resources decisions (e.g., hiring/firing; compensation and setting career paths for the personnel employed within your unit; reorganizing your unit; creation of new jobs).

If you and/or any of your subordinates make the decision without the knowledge of your supervisor, you and/or others of your unit are considered to have all influence

Table 4. Checklist for estimating of variable "decentralization".

\begin{tabular}{|l|l|l|l|l|l|l|l|l|l|}
\hline \multicolumn{9}{|c}{$\begin{array}{l}\text { My unit has } \\
\text { all influence }\end{array}$} & $\begin{array}{c}\text { My superior } \\
\text { and I have } \\
\text { about the } \\
\text { same influence }\end{array}$ \\
\hline 1 & Strategic decisions & 1 & 2 & 3 & 4 & 5 & 6 & 7 \\
\hline 2 & Investment decisions & 1 & 2 & 3 & 4 & 5 & 6 & 7 \\
\hline 3 & Marketing decisions & 1 & 2 & 3 & 4 & 5 & 6 & 7 \\
\hline 4 & $\begin{array}{l}\text { Decisions regarding } \\
\text { internal processes }\end{array}$ & 1 & 2 & 3 & 4 & 5 & 6 & 7 \\
\hline 5 & $\begin{array}{l}\text { Human resource } \\
\text { decisions }\end{array}$ & 1 & 2 & 3 & 4 & 5 & 6 & 7 \\
\hline
\end{tabular}

\section{CONCLUSION}

The aim of the conducted research was to investigate the impact of the determinants - subunit interdependence and knowledge transfer costs, on the level of decentralization and PMSs using as an example the sub-divisional units from the Bulgarian facilities and hospitals. The Bulgarian structural organization of decentralization level has specific impact on the social health care system competitiveness. According to our theoretical research there were suggested three hypotheses about the impact of the mentioned above factors. There were developed checklists and was carried out an investigation among 78 managers from 18 subunits of the organization. As a result, there were summarized statistics concerning the research variables. The next step of the research will be to estimate statistical relations between variables and their significance. There will be proposed particular coefficients of the models for simultaneously decision making for the level of decentralization and the structure of PMSs (Petkova - Georgieva, 2018).

\section{REFERENCE LIST}

Bouwens, J., Abernethy, M.A. (2000). The Consequences of Customization on Management Accounting System Design, Accounting, Organizations and Society, 25(3), 2000.

Christie, A.A., M.P. Joye, R.L. Watts, (1993). Decentralization of the Firm: Theory and Evidence, WP, 
University of Rochester,1993.

Jensen, M.C., Meckling, W.H., (1992). Specific and General Knowledge and Organizational Structure, in: Werin, L. and Wijkander, H. (Eds.) Contract Economics, Blackwell Publishers, Cambridge, 1992.

Kaplan, R.S., A.A. Atkinson, (1998). Advanced Management Accounting, Prentice Hall, Upper Saddle River, NJ, 3rd edition, 1998.

Keating, A.S., (1997). Determinants of Divisional Performance Evaluation Practices, Journal of Accounting and Economics, 24, 1997.

Khandwalla, P.N., (2010). The Effect of Different Types of Competition on the Use of Management Controls, Journal of Accounting Research, 10(2), 2010.

Milgrom, P., Roberts J., (2016). Economics, Organization and Management, Prentice-Hall, Upper-Saddle River, NJ 2016.

Milgrom, P., Roberts, J., (2015). Complementarities and Fit: Strategy, Structure and Organizational Change in Manufacturing, Journal of Accounting and Economics, 19, 2015.

Nagar, V., (2014). Interrelations Among a Firm's Delegation and Incentive Compensation Choices, WP, University of Michigan Business School, 2014.

Simons, R. (2017). Levels of Control, Accounting Control Systems and Business Strategy, Accounting, 4, 2017.

Petkova - Georgieva, St., (2018). Basic Problems to Solve in Strategic Controlling Implementation, annual of "Prof. Dr. Assen Zlatarov", pp. 71 - 77, v. XLVII, book 2, Burgas, Bulgaria, 2018, ISSN 2603-3976.

Todorov, M. (2018a). Recent advances in computational chemistry for identification of ligands for biological receptors: interdisciplinary aspects, Medical Science Pulse 2018 (12) 1, pp. 12-15, DOI: 10.5604/01.3001.0011.6670, ISSN: 2544-1620.

Todorov, M.(2015a) Computational tools for prediction of nuclear receptor mediated effects. East. Acad. J., 2015, 1, pp. 46-56, ISSN:2367-7384.

Terziev, V., Petkova - Georgieva, S. (2019). The performance measurment system key indicators and the determinants impact on the level of decentralization using as an example a subdivisional unit from the Bulgarian social health and care experience. // Proceedings of SOCIOINT 2019-6th International Conference on Education, Social Sciences and Humanities 24-26 June 2019- Istanbul, Turkey, International Organization Center of Academic Research, Istanbul, Turkey, 2019, pp. 515-524, ISBN: 978-605-82433-6-1

Terziev, V., Petkova - Georgieva, (2019a). S. A research study of nonlinearity experiencing in the rate of current account deficit to the Bulgarian health and care national product. // Proceedings of SOCIOINT 2019- 6th International Conference on Education, Social Sciences and Humanities 24-26 June 2019Istanbul, Turkey, International Organization Center of Academic Research, Istanbul, Turkey, 2019, pp. 525-533, ISBN: 978-605-82433-6-1. 